Bond University

Research Repository

\title{
Utility of incident and injury surveillance systems for incident and injury risk management in tactical populations
}

Pope, Rodney R; Orr, Rob Marc

Published in:

Journal of Science and Medicine in Sport

DOI:

10.1016/j.jsams.2017.09.401

Licence:

CC BY-NC-ND

Link to output in Bond University research repository.

Recommended citation(APA):

Pope, R. R., \& Orr, R. M. (2017). Utility of incident and injury surveillance systems for incident and injury risk management in tactical populations. Journal of Science and Medicine in Sport, 20(s2), s103. [172].

https://doi.org/10.1016/j.jsams.2017.09.401

\section{General rights}

Copyright and moral rights for the publications made accessible in the public portal are retained by the authors and/or other copyright owners and it is a condition of accessing publications that users recognise and abide by the legal requirements associated with these rights.

For more information, or if you believe that this document breaches copyright, please contact the Bond University research repository coordinator 


\title{
Utility of Incident \& Injury Surveillance Systems for Incident \& Injury Risk Management
}

\author{
Rod Pope, Rob Orr
}

PURPOSE: To explore differences between various incident and injury surveillance systems (IISS) in their designs and in the rates of injuries they report for army personnel, and to consider ways to optimise the utility of IISS to inform future efforts to control both cyclical and emergent incident and injury risks.

METHODS: Rates of injury reported for Australian Army personnel based on the Army's Work Health and Safety incident reporting system and rates of injury reported for Australian Army personnel and for US Army personnel based on 'point-of-care' injury surveillance systems were extracted from results of prior research by the authors. ${ }^{1}$ Factors affecting the utility of IISS were also ascertained from previous research.

RESULTS: Rates of injury reported for Australian Army personnel based on the Army's Work Health and Safety incident reporting system are substantially lower than rates of injury reported for Australian Army personnel and for US Army personnel based on 'point-of-care' injury surveillance systems. ${ }^{1}$ However, the latter do not allow for identification of 'near misses', dangerous exposures, hazards and similar incidents and factors that affect risk but do not result in immediate injury. ${ }^{1}$ The utility of IISS is affected by a range of factors, including: ${ }^{1,2}$ data structure; data collection approaches; data completeness and integrity; context; organisational culture; communication between stakeholders; and analysis and reporting capabilities and timeliness.

CONCLUSIONS: The utility of IISS is heavily dependent on the system accessibility, analysis and reporting capabilities available in real time to commanders, and on tactical and risk management contexts. When tactical taskings and associated incident and injury risks are cyclical or repeated, well-designed IISS using hybrid data collection approaches will be of high utility for risk management. In tactical units engaged in new and emerging operational contexts, IISS are less useful to inform management of emerging and novel incident and injury risks, and IISS should be supplemented by other key approaches to incident and injury risk identification and assessment, thus bringing together population health and work health and safety approaches to incident and injury risk management.

\section{REFERENCES:}

Pope, R \& Orr, R (2017). Incidence rates for work health and safety incidents and injuries in Australian Army Reserve vs full time soldiers, and a comparison of reporting systems. Journal of Military \& Veterans Health, 25(2): 16-25

McKinnon A, Ozanne-Smith J, Pope R (2009). Optimizing the utility of military injury surveillance systems: A qualitative study within the Australian Defence Force. Military Medicine, 174(5): 470-478 